\title{
Effects of varying degrees of legitimacy in the attribution of responsibility for negative events'
}

\author{
Morgan M. Worthy, Jack M. Wright and Marvin E. Shaw \\ UNIVERSITY OF FLORIDA
}

\begin{abstract}
Team A (2 confederates and 1 naive S) and Team B (3 naive Ss) played a game in which tokens were won or lost. On certain loss trials, the confederates of Team A attributed the loss to the naive S, either legitimately or nonlegitimately. This accusation caused the accused to become less willing to interact further in similar situations, and to lower his interest in the game. Observers were less willing to interact with the accused than with others in the legitimate, and with both the accused and accusers in the nonlegitimate condition. Results were interpreted in terms of defensiveness, perception of reality, and compatibility.

\section{Problem}

Many studies have been concerned with variables influencing the perception of social causality and attribution of responsibility (Piaget, 1932; Thibaut \& Riecken, 1955; Strickland, 1958; Pepitone, 1958; Wright, 1961; Shaw \& Sulzer, 1964). Equally important, however, are the effects of having responsibility attributed to a person upon that person's behavior and upon the reactions of persons who observe the attribution. Since the attribution of responsibility implies evaluation of the individual, it should not be a matter of indifference with respect to the individual's subsequent behavior. Although these effects are undoubtedly influenced by a variety of variables, the present study is limited to the effects of attribution of responsibility (AR) for negative events under legitimate and nonlegitimate conditions upon the behavior of the target person (the accused) and of relatively uninvolved observers.

\section{Method}

Ten groups of six persons each (college undergraduates) were run in a game situation in which two threeperson teams played simultaneously. Ostensibly, wins and losses were contingent upon each team's plays matching the plays of the other team (teams played alternately). Wins or losses (of tokens) were paid by or to the experimenter (E). Team A was composed of one naive $\mathrm{S}$ and two confederates, whereas Team B was composed of three naive Ss. Initially, each S was given 50 tokens, each worth one point. Each time the group won, E paid the group 9 tokens - to be divided among the group members however they chose. Similarly, the group paid 9 tokens to $\mathrm{E}$ each time the team lost. Again, distribution of payment was decided by the team members.

Players could not see the plays of the opposing team, so $\mathrm{E}$ had complete control of wins and losses through his report. The win-loss sequence was standardized in advance, each team losing 8 times and winning twice. Re- sponsibility for losses by Team A was attributed to the accused through the actions of the confederates. One confederate (the instigator) stated that the accused was responsible for certain losses (6 of the 8 ) and the other confederate (the collaborator) agreed. On the first loss, the accused was required to pay no more than the confederates, but on succeeding losses the accused was required to pay a larger and larger proportion of the loss (the accused paid 3,5,5,7,7, and 9 tokens on the 6 loss trials for which he was held responsible).

For half of the groups the confederates' AR to the accused was legitimatized by E's explicit statement that the accused was the one who had played incorrectly, whereas for the other half (the nonlegitimate condition) E simply stated that Team A had lost. Procedures were the same for Team B except that in the legitimate condition $\mathrm{E}$ stated that each observer played incorrectly an equal number of times.

At the end of the 10 trials allowed each team, each $\mathrm{S}$ rated their satisfaction with fellow team members, their interest in the game, and perceived cooperation and ability of their own and of the opposing team. Finally, Ss were told that they would play a second game, working in pairs. By closed ballot, each Sbid for the opportunity to play with each of the others present.

\section{Results}

The major dependent variable was the "bid for others" score, which presumably reflects willingness to interact with others. Table 1 gives the mean bids for each of the 4 categories of Ss. Analysis of variance revealed no significant differences among bids for others by the accused. Significant differences were found among bids by observers as a function of Legitimacy $(\mathrm{F}=9.22$; $\mathrm{df}=$ 3, 24; $\mathrm{P}<.001)$ and the Legitimacy $\mathrm{x}$ Persons Interaction $(\mathrm{F}=4.25 ; \mathrm{df}=3,24 ; \mathrm{P}<.05)$. In the legitimate condition the major difference was between the accused and others; in the nonlegitimate bids were ordered (from lowest to highest) as follows: accused, instigator, collaborator, observers.

The effects upon the accused were revealed most clearly in ratings. He rated his interest in the game lower in the legitimate (4.3) than in the nonlegitimate condition (8.6), whereas the observers rated their interest higher in the legitimate (7.6) than in the nonlegitimate condition (4.4). The Legitimacy $\mathrm{x}$ Rater interaction was significant $(\mathrm{P}<.05)$.

Analysis of satisfaction ratings yielded significant differences attributable to Team Rated $(\mathrm{P}<.01)$, Team $\mathrm{x}$ Rater interaction $(\mathrm{P}<.001)$, and Legitimacy $\mathrm{x}$ Rater interaction $(\mathrm{P}<.05)$. The accused rated satisfaction 
Table 1. Mean Bids to Play With Other Persons by the Accused and by Observers

\begin{tabular}{|c|c|c|c|c|c|}
\hline \multirow{2}{*}{ Bidder } & \multirow{2}{*}{ Condition } & \multicolumn{4}{|c|}{ Persons Bid Upon } \\
\hline & & Accused & Instigator & Collaborator & Observers \\
\hline \multirow{2}{*}{ Accused } & Legitimate & --- & 6.00 & 6.40 & 3.33 \\
\hline & Nonlegitimate & --- & 8.00 & 3.40 & 5.33 \\
\hline \multirow{2}{*}{ Observers } & Lefitimate & 2.68 & 8.06 & 7.12 & 7.10 \\
\hline & Nonlegitimate & 4.14 & 5.76 & 8.46 & 15.12 \\
\hline
\end{tabular}

higher in his own team in the legitimate condition (11.1 vs. 7.6) but higher in the other team in the nonlegitimate condition (11.6 vs. 8.9). The Observers rated satisfaction higher in their own team in both legitimacy conditions (13.6 vs. 5.7). For ratings of cooperation, only the Team $\mathrm{x}$ Rater and Legitimacy $\mathrm{x}$ Team $\mathrm{x}$ Rater Interactions were significant $(\mathrm{P}<.01$ in each case). The pattern was similar to ratings of satisfaction except that Observers rated cooperation of the other team very low (4.3) under nonlegitimate conditions.

Analysis of ratings of game-playing ability indicated significant differences between Raters $(\mathrm{P}<.05)$ and between Teams Rated $(\mathrm{P}<.05)$. Observers rated ability higher than did the accused (10.7 vs. 8.8$)$, and one team was rated as having more ability than the other team by both the accused and the observers (10.8 vs. 8.7$)$. It is worth noting, however, that in the legitimate condition the accused rated the other team as having slightly more ability than his own (8.9 vs. 7.8 ).

\section{Diseussion}

Assuming that motivation was initially equal for all naive Ss, the results of this experiment indicate defensiveness on the part of the accused. This defensiveness is reflected by the relatively low ratings by the accused of interest in the game and of the game-playing ability of his own team. Similarly, his ratings of satisfaction and cooperation were higher in the legitimate than in the nonlegitimate condition. It is noteworthy that the accused did not reject or directly attack his accusers; however, he tended to reject the collaborator more than the instigator.

The observers' reactions seem to be due to two factors: a reality factor and a compatibility (or cooperation) factor. Under all conditions, the accused is a loser in one or another sense. In the legitimate condition, he is designated by an authority figure (E) as being at fault. In the nonlegitimate condition, he is a loser not only by accusation by fellow team members (strikingly accepted by observers), but also on the basis of "gamesmanship" in that he is forced by others to pay a larger proportion of losses. In reality, he appears to be a poor candidate for a partner. The compatibility factor appears primarily in the nonlegitimate condition, where the confederates' accusations are not justified. Their behavior is perceived by the observers as uncooperative, as shown by observers' very low ratings of other team cooperation. Individuals in our culture prefer to work with cooperative partners.

In summary, the effects upon the accused of attribution of responsibility for a negative event was to elicit a defeisive reaction, especially when there was a realistic basis for the attribution. This defensive reaction was expressed by a reduction in willingness to continue interactions in similar situations, a denial of interest in the team activity, and lowered ratings of his team's ability. For observers, the effect was to make them less willing to interact with the accused, but more willing to interact with the instigator, a reaction apparently based upon perceptions of him as an effective, knowledgeable person.

\section{References}

PEPITONE, A. Attribution of causality, social attitudes, and cognitive matching processes. In R. Tagiuri and L. Petrullo (Eds.) Person perception and interpersonal behavior. Stanford: Stanford Univer. Press, 1958. Pp. 258-276.

PIAGET, J. The moral judgment of the child. New York: Meridian, 1932.

SHAW, M. E., \& SULZER, J. L. An empirical test of Heider's levels in attribution of responsibility. J. $a b n$. soc. Psychol., 1964, in press.

STRICKLAND, L. H. Surveillance and trust. J.Pers., 1958, 26, 200-215.

THIBAUT, J. W., \& RIECKEN, H. W. Some determinants and consequences of the perception of social causality. J. Pers., 1955, 24, 113-133.

WRIGHT, J. M. Attribution of social responsibility and self concept. Dissert. Abstr., 1961, 21, No. 11, 1961.

\section{Note}

1. The authors wish to thank Paul Caron, Larry Young, and Alex Kronstadt for their assistance in collecting the data for this experiment. 